\title{
A AQUISIÇÃO DA MORFOLOGIA VERBAL EM UM ESTUDO COMPARATIVO ENTRE CRIANÇAS BILÍNGUES E MONOLÍNGUES
}

Liane Barreto Silva ${ }^{1}$

Aline Lorandi ${ }^{2}$

\section{RESUMO}

Este trabalho tem por finalidade apresentar uma pesquisa de campo voltada para a aquisição morfológica. Foram comparados os dados de uma criança bilíngue (português e espanhol) e outra monolíngue (português), a fim de problematizar questões referentes à morfologia verbal do português. Como pressuposto teórico, o trabalho baseia-se nos estudos sobre o bilinguismo de Romaine (2004), entendendo que o desenvolvimento de duas línguas concorrentes no sistema linguístico acarreta diferenças no vocabulário entre bilíngues e monolíngues. A metodologia empregada no trabalho foi composta por testes elaborados a partir dos estudos de Berko (1958) e de Lorandi (2011) e, por serem escassos os estudos sobre aquisição da morfologia, esta pesquisa diferencia-se porque desenvolveu uma metodologia específica para a coleta de dados, a qual evidencia o conhecimento verbal das participantes. Os resultados obtidos a partir do levantamento dos dados mostraram que realmente existem diferenças relevantes de vocabulário entre as participantes, mas provocaram reflexões referentes ao falante bilíngue e a escolha da língua que utiliza para se comunicar, dependendo do contexto e, principalmente, de seu interlocutor. Espera-se com este trabalho complementar os estudos sobre bilíngues, bem como aprimorá-lo em trabalhos futuros a fim de confirmar possíveis resultados.

Palavras-chave: Aquisição da Linguagem. Morfologia Verbal. Bilinguismo. Metodologia.

\section{INTRODUÇÃO}

O presente trabalho buscou fazer um levantamento na produção do 
vocabulário verbal de crianças monolíngues e bilíngues, a fim de fazer uma comparação entre os sistemas morfológicos dessas crianças, mas também olhar para a aquisição de duas línguas simultaneamente nos aspectos referentes à produção de verbos.

Trata-se de uma pesquisa de campo em que foram coletados dados de duas participantes, uma bilíngue e outra monolíngue, por meio de uma metodologia elaborada exclusivamente para a produção verbal.

Usou-se, como pressuposto teórico, os estudos de Romaine (2004) sobre a aquisição bilíngue, bem como as referências de Bialystok (2009), Eve Clark (2010) e Edwards (2006), que inferiram questões importantes acerca do vocabulário em bilíngues, que serão mais bem explorados nas seções seguintes.

\section{REFERENCIAL TEÓRICO}

\subsection{Bilinguismo}

(Re)pensar o desenvolvimento linguístico e cognitivo de bilíngues sugere refletir sobre inúmeros fatores que possam justificar e esclarecer questões que perpassam as concepções teóricas existentes e que seriam de grande importância para o entendimento desse processo instigante. A própria definição do que seria bilinguismo é complexa, havendo vários conceitos em circulação, visto que existem diversas situações em que um "monolíngue" pode ter contato com outra língua e acabar incorporando-a em seu sistema linguístico. Com isso, como definir um indivíduo bilíngue? Seria pelas circunstâncias de uso das línguas adquiridas?Pela competência em usá-las em determinada situação? Ou o quanto conhece em vocabulário da segunda língua?

Romaine (2004) define tipos de bilinguismo, qualificando-os de acordo com a comunidade em que essas crianças estão inseridas, bem como de seu contato com a segunda língua. Para os fins deste trabalho, situa-se que a informante bilíngue selecionada é do tipo 1, de acordo com a classificação de Romaine, sendo que os pais têm diferentes línguas maternas, mas algum conhecimento sobre a língua do outro. A língua de um dos pais é a língua dominante e cada pai fala a sua língua com/para a criança desde o nascimento.

Romaine especifica, ainda, características de bilíngues que são essenciais 
para se pensar no processo de aquisição de duas línguas concorrentes, as quais aparecem arroladas a seguir: a) crianças bilíngues não têm o mesmo número de palavras em seu vocabulário se comparadas a monolíngues; b) cada língua se desenvolve independentemente, assim como seria em uma criança monolíngue; c) a aquisição em bilíngues é mais demorada em comparação a monolíngues; d) a criança prefere uma das línguas, e a aquisição do domínio dessa língua determina o desenvolvimento de construções e categorias que são combinadas em ambos os sistemas.

Tais questões evidenciam o quanto é rica a forma como se realiza o processo de aquisição bilíngue e as distinções que são feitas no momento em que a criança escolhe um dos idiomas para se tornar a sua língua materna. Pode-se entender esse processo de escolha levando em consideração o contexto, a sociedade e o input recebido. Por exemplo, em uma situação em que os pais possuem línguas nativas distintas, sendo que uma das línguas é a dominante na sociedade em que o investigado vive, a criança recebe os dois inputs linguísticos, e o que determinará a escolha da sua L1 será um fator crucial como a língua dominante nessa sociedade.

Em estudos recentes, a neurociência traz evidências de que bilíngues apresentam algumas diferenças comportamentais e vantagens neurais sobre indivíduos monolíngues. Dentre elas, encontramos que bilíngues apresentam uma melhor função executiva e vantagens cognitivas que vão além do domínio linguístico. Porém, possuem algumas desvantagens referentes ao nível lexical: a mistura das duas línguas e o número de palavras adquiridas. Bilíngues possuem dois léxicos competindo e o número de itens conhecidos é dividido entre os dois, por exemplo, uma criança monolíngue, com dois anos de idade, produz de 200 a 600 palavras (CLARK, 2010), uma bilíngue dividiria esse número entre as duas línguas concorrentes. A partir disso, evidencia-se uma suposta vantagem do vocabulário lexical da participante monolíngue em relação à bilíngue.

Bialystok (2009) afirma que uma das características marcantes que distinguem bilíngues de monolíngues é a necessidade de controlar a atenção para um sistema específico, tendo dois sistemas competitivos e ativos. Essa necessidade de monitorar duas línguas e selecionar a mais apropriada exercita regiões cerebrais, tornando-as mais flexíveis e aumenta a habilidade cognitiva de processar informações.

Mesmo que ainda se saiba pouco a respeito da aquisição de duas línguas 
simultâneas, alguns estudos já concluem por algumas vantagens cognitivas em relação aos monolíngues. Porém, o bilíngue pode ter alguma desvantagem no vocabulário adquirido e na rapidez do processo, pois cada língua possui sua sistematização e especificidade, por exemplo, no espanhol existem tipos de irregularidades, referentes aos verbos, diferentes daquelas da morfologia do português. Em bilíngues do português e do espanhol, além de possuir desvantagens lexicais, o bilíngue tem que lidar com essas sistematizações distintas e concorrentes na aquisição morfológica. Na próxima seção será detalhada essa diferenciação referente à sistematização de cada uma das línguas.

\subsection{Morfologia}

Nesta seção serão abordadas informações pertinentes à morfologia verbal das línguas abordadas no trabalho: o português e o espanhol.

\subsubsection{Morfologia verbal do português}

Para entender o processo morfológico verbal é necessário compreender como se formam esses vocábulos.

O vocábulo flexional verbal assume duas noções diferentes por meio de seus morfemas gramaticais: a de tempo-modo e a de número-pessoa, que correspondem às desinências ou sufixos flexionais. Esses morfemas se anexam ao radical da palavra, que representa o léxico - a significação, formando assim a estrutura verbal: Tema (radical + vogal tema) + DMT (modo e tempo verbal) + DNP (número e pessoa). A vogal temática ( $a, e$ ou $i)$ representa a conjugação a que o verbo pertence. Os verbos classificam-se, ainda, em regulares e irregulares. Os verbos regulares, o padrão geral da língua portuguesa, preservam o mesmo radical em todos os tempos, sendo esse invariável. Os irregulares possuem algumas alterações nos sufixos flexionais, porém o que é verdadeiramente importante é a mudança em seu radical que cria padrões morfológicos verbais organizados de forma específica (CÂMARA JR.,1973). Os verbos "andar" e "fazer" são exemplos de verbos regulares e irregulares, respectivamente. Observe a conjugação destes verbos nos quadros abaixo: 
Quadro 1 - Verbos regulares

\begin{tabular}{|l|l|l|l|l|l|l|}
\hline Andar & Eu & Tu & Ele & Nós & Vós & Eles \\
\hline Presente & Ando & Andas & Anda & Andamos & Andais & Andam \\
\hline $\begin{array}{l}\text { Pretérito } \\
\text { Perfeito }\end{array}$ & Andei & Andaste & Andou & Andamos & Andastes & Andaram \\
\hline
\end{tabular}

Quadro 2 - Verbos irregulares

\begin{tabular}{|l|l|l|l|l|l|l|}
\hline Fazer & Eu & Tu & Ele & Nós & Vós & Eles \\
\hline Presente & Faço & Fazes & Faz & Fazemos & Fazeis & Fazem \\
\hline $\begin{array}{l}\text { Pretérito } \\
\text { Perfeito }\end{array}$ & Fiz & Fizeste & Fez & Fizemos & Fizestes & Fizeram \\
\hline
\end{tabular}

Comparando as formas verbais acima, por meio da depreensão dos seus morfemas, nota-se que o radical do verbo "fazer" muda conforme o tempo e a pessoa verbal, caracterizando-se como irregular. Já o verbo "andar" continua com o mesmo radical nos dois tempos, caracterizando-se como regular.

\subsubsection{Morfologia verbal do espanhol}

Os verbos, em espanhol, são semelhantes aos do português em relação à sua formação, pois sofrem processos de flexão, com distinções nas irregularidades verbais e em como se entende a estrutura morfológica dos verbos. Neste trabalho, adota-se a estrutura de Alcoba (1991), que, por meio da depreensão morfológica, percebe os verbos como: RAIZ + VT + TAM + NP, em que a raiz significa o morfema lexical, VT a vogal temática/as conjugações verbais, TAM são as desinências de tempo, aspecto e modo e NP refere-se à desinência de número e pessoa. Os verbos também se classificam em regulares e irregulares, sendo regulares os que possuem a raiz invariável e irregulares os que sofrem mudanças em seu radical.

Segundo Busquets e Bonzi (1993), os verbos regulares e irregulares diferenciam-se também na quantidade de formas entre as conjugações. Os verbos 
regulares estão, em sua grande maioria, na primeira conjugação e os irregulares em segunda conjugação.

Munõz e Barreto (1999) apresentam os tipos de irregularidades dos verbos espanhóis. Essas irregularidades estão relacionadas ao radical da palavra, são irregularidades vocálicas, consonantais e casos especiais de mudança do radical, presentes no quadro abaixo:

\section{Quadro 3 - Tipos de irregulares dos verbos}

\begin{tabular}{|c|c|c|}
\hline Irregularidade no Radical & Contexto & Exemplo \\
\hline Vocálica & $\begin{array}{c}\text { Afeta a vogal temática da } \\
\text { raiz. }\end{array}$ & Pensar = yo pienso \\
\hline Consonantal & $\begin{array}{l}\text { 1) Alternância de um } \\
\text { elemento do radical; } \\
\text { 2) Acréscimo de um } \\
\text { elemento; uma consoante }\end{array}$ & 1) decir = yo digo \\
& 2) Traer = yo traigo \\
& $\begin{array}{c}\text { Nesses casos, os verbos } \\
\text { apresentam diferenças na } \\
\text { raiz, nos diferentes }\end{array}$ & Presente $=$ yo He \\
& tempos verbais. & Pretérito= hube \\
\hline
\end{tabular}

Após essa breve abordagem da morfologia das línguas envolvidas neste trabalho, o próximo passo é buscar entender o que os estudos sobre Aquisição da Linguagem mencionam sobre a aquisição dos aspectos morfológicos.

\subsection{Aquisição da linguagem e aquisição morfológica}

A aquisição da linguagem é um processo complexo que começa a ser desenvolvido desde o feto. Assim que inicia sua exposição a um input linguístico, do qual extrai informações, o indivíduo inicia sua jornada de aquisição da linguagem. Desde cedo,todo ser humano em desenvolvimento típico vai depreender de um contínuo de fala, fonemas e morfemas, a partir da segmentação, e assim começar o processo de aquisição de uma ou mais línguas. No decorrer da história, inúmeros teóricos tentaram desvendar e explicar esse fenômeno linguístico (INGRAM, 1989; 
KARMILOFF, KARMILOFF-SMITH, 2001; CLARK, 2010; LORANDI; CRUZ; SCHERER, 2011b).

A aquisição da linguagem ainda instiga muitos pesquisadores e ganha espaço nos estudos da neurociência e das relações entre cognição e linguagem. As noções de que se parte neste trabalho têm seu escopo no trabalho de Karmiloff-Smith (1992), que propõe o desenvolvimento da linguagem a partir de um processo de modularização gradual em que o conhecimento estaria disponível ao sistema linguístico com o avanço dos níveis de representação mental.

Existem na literatura muitas divergências sobre qual a ordem de aquisição dos subsistemas linguísticos, como, por exemplo, a estudiosa Eve Clark (2010), que defende a ideia da aquisição da semântica junto, ou antes, da aquisição morfológica.

A aquisição da morfologia se realiza no momento em que o falante começa a depreender morfemas e analisar esses conhecimentos, e isso permite ao pesquisador refletir sobre como as crianças lidam com os recursos morfológicos da língua. A partir dos dois anos de idade, essa análise fica mais rebuscada, e as crianças começam a avaliar mais detalhadamente as formas linguísticas, analisando internamente os vocábulos. Um exemplo desse fenômeno são as formas morfológicas variantes ${ }^{3}$, em que crianças regularizam verbos irregulares. Pode-se pensar nessa regularização como decorrente da frequência do input que a criança recebe. Dessa forma verbal, afirma Eve Clark (2010, p. 184) que:

as formas mais produtivas são aquelas que aparecem em maior número de situações. Elas [as crianças] tendem a usar as formas mais produtivas mais frequentemente do que as menos produtivas, que são usadas somente mais tarde.

Com isso, na forma regularizada fazi a criança substitui o radical fiz- por fazpor ser o mais recorrente na língua e acaba regularizando essa forma verbal (LORANDI, 2007).

É importante salientar que, especialmente no Brasil, a aquisição da morfologia não é uma área muito explorada e, portanto, há poucos trabalhos disponíveis para revisão da literatura sobre o assunto. Também em função disso, entende-se como justificada a relevância deste trabalho.

As diferenças entre o que a criança entende e o que ela produz, bem como o modo como ela acessa seu conhecimento para produzir formas verbais ou para lidar com elas de modo a manipular seu conhecimento como um objeto do pensamento, 
manifestando-se verbalmente sobre ele, pode levar à diferenciação entre uso de formas verbais adquiridas e consciência morfológica. Com relação a esse aspecto, Lorandi (2011), a partir dos estudos de Karmiloff-Smith, elabora um conceito de consciência, relacionando esse fenômeno linguístico ao desenvolvimento do conhecimento, contemplando não somente a morfologia, mas qualquer subsistema linguístico. Dessa forma, consciência seria a capacidade de acessar e expressar o conhecimento, com o alcance de determinados níveis de representação mental, nos quais o conhecimento está em um formato tal em que é possível mostrar sensibilidade aos recursos da língua; trabalhar em tarefas off-line; e pronunciar-se sobre o conhecimento (LORANDI, 2011).

\section{METODOLOGIA}

Nesta seção será abordado como foi desenvolvida esta pesquisa de campo. Trata-se de um estudo transversal, em que foram feitas coletas com duas participantes do sexo feminino. A metodologia para a obtenção dos dados foi elaborada pelas pesquisadoras no intuito de que se produzissem verbos, nas duas línguas abordadas no trabalho.

As coletas foram realizadas na escola em que as participantes estudavam, porém um dos testes foi aplicado em suas residências. É importante salientar que as coletas foram realizadas em momentos distintos para as duas informantes, sendo que, para a criança bilíngue, foram aplicados testes em português e em espanhol com quatro dias de intervalo entre a aplicação do teste em português e do teste em espanhol. As coletas foram gravadas com câmera fotográfica e depois transcritas para um melhor entendimento dos dados obtidos.

\subsection{Participantes}

Para a realização deste estudo, foram entrevistadas duas meninas, que são colegas de escola e pertencem à mesma classe social. Como se trata de um estudo comparativo entre bilíngues e monolíngues, foram feitas coletas com uma participante monolíngue, a I. (4;8) e com uma participante bilíngue, a C. $(4 ; 6)$.

A participante monolíngue é natural de Porto Alegre-RS e veio residir em Bagé-RS com dois anos de idade. A participante bilíngue nasceu em Bagé e tem 
contato com a língua portuguesa por ser a língua materna de sua mãe, além de estar em uma comunidade em que esta língua é a dominante. O contato com a língua espanhola se dá por meio de seu pai, que é uruguaio e também por meio de artefatos de identidade uruguaia, assim como também com livros e revistas nessa língua. C $(4 ; 6)$ mora em Bagé, mas visita os parentes com frequência na cidade de Aceguá, fronteira entre Brasil e Uruguai. Ao questionar os pais, professores e ajudantes de $C(4 ; 6)$, todos responderam que a menina sabe falar espanhol, porém só se comunica nesse idioma com seu pai.

\subsection{Testes}

Os dados pretendidos exigiam uma metodologia que fosse voltada para a produção de verbos, além de representar para as participantes um momento de descontração, de brincadeira, em que se sentissem à vontade. Para isso, foram elaborados quatro testes, cada um com sua especificidade, para uma melhor depreensão de vocábulos verbais.

\subsubsection{Teste 1: Jogo das princesas}

\subsubsection{Contexto experimental}

O jogo das princesas é um jogo de tabuleiro, em que a participante joga o dado e, dependendo do número que sair, ela anda casas até chegar ao final no jogo. Porém, para poder avançar, a criança deve falar algo sobre as figuras que estão ilustradas no tabuleiro (momento de fala espontânea) e, quando parar em uma casa que contém uma ação, ela é instigada a comentar sobre tal atividade. Por exemplo, visto que os testes visam à produção verbal, as imagens contidas no tabuleiro representam alguma ação, como pentear os cabelos, dançar uma música, sujar o vestido, etc. $O$ teste foi aplicado na escola infantil que as participantes frequentam. A escola cedeu uma sala para que pesquisadora e participante pudessem ficar a sós, de modo que não fossem interrompidas. 


\subsubsection{Contexto procedimental}

Buscou-se envolver a criança de forma que ela se sentisse à vontade para responder às perguntas feitas no decorrer da brincadeira. Ao avançar nas etapas do jogo, a criança podia "cair" em uma das casas com perguntas ou comentários do jogo: ficou bem maquiada! Você está cansada! Vamos comer? Que pena, sujou o vestido! Limpe o castelo! Vamos fazer uma dança? Que tal arrumar o cabelo? Esqueceu de pegar as flores! Você achou o sapatinho de cristal. A partir dessas incitações e comentários, a participante era questionada se já tinha praticado tais ações, além de ser instigada a falar sobre outras ações que lembrava a partir das imagens do tabuleiro ${ }^{4}$. O jogo tem duas versões, uma em português e uma em espanhol, a qual foi utilizada para ser aplicada à criança bilíngue.

\subsubsection{Teste 2: Histórias em família}

\subsubsection{Contexto experimental}

Esse teste teve por objetivo fazer com que as crianças produzissem 0 máximo de verbos possíveis, por meio do relato de histórias de viagens com a família, de forma espontânea. A tática para a produção dos dados pretendidos foi tornar o ambiente agradável, por isso o teste foi aplicado em suas residências, proporcionando-Ihes um ambiente descontraído. O material para coletar os dados foram álbuns de fotografias das participantes.O teste foi aplicado na sala da casa das crianças, em meio a almofadas, para que fosse similar ao momento de contação de histórias da escola em que estudam.

\subsubsection{Contexto procedimental}

A pesquisadora convidou as crianças para mostrarem suas fotos e, a partir disso, narrarem que histórias havia por trás das imagens. Para que não fosse somente uma apresentação da família, foram feitas perguntas, a partir do contexto das fotos: o que é isso? Você viaja muito com sua família? Como se anda de cavalo? etc. $\mathrm{O}$ objetivo era que a criança falasse o que quisesse a partir da temática "histórias em família" e as perguntas decorrentes dela. 


\subsubsection{Teste 3: O que é isso?}

\subsubsection{Contexto experimental}

Esse teste é um jogo de descrição de imagens de desenhos infantis. As figuras representavam cenas de ação para propiciar a produção verbal. Ao todo, foram nove figuras com cenas distintas. $O$ teste foi aplicado na escola infantil que as participantes estudam.

\subsubsection{Contexto procedimental}

O jogo inicia-se com as figuras no chão, viradas para baixo, e a pesquisadora convida a criança a escolher uma imagem. Ao descobrir que desenhos contêm aquelas figuras, as participantes foram instigadas a dizer quais personagens eram, o que estavam fazendo e, posteriormente, se elas já haviam praticado as ações apresentadas nas imagens.

\subsubsection{Teste 4: O mundo de Mimão}

\subsubsection{Contexto experimental}

Esse teste foi produzido para averiguar a habilidade das participantes ao lidar com pseudopalavras ${ }^{5}$. As atividades basearam-se nos testes de produção morfológica de Lorandi (2011). Foi apresentado às crianças um extraterrestre, 0 Mimão, e, a partir disso, as crianças respondiam a perguntas sobre a história que o Mimão pediu à pesquisadora para contar. As perguntas giravam em torno das pseudopalavras mitrar, piscarejar, cholavar, gifincar e jamir ${ }^{14}$, que no contexto da história significavam beber, miar, chorar, gripar e dançar. Nesse caso, utilizou-se proximidade de significação. Essa proximidade deveu-se à importância da compreensão da palavra para os resultados deste estudo, porque é relevante a criança entender antes de produzir, visto que a compreensão precede a produção (CLARK, 2009). As crianças tinham que responder às perguntas aplicando 
morfemas gramaticais verbais nas pseudopalavras. O teste foi elaborado em português e em espanhol para a criança bilíngue, sendo aplicado na escola.

\subsubsection{Contexto procedimental}

A pesquisadora apresentava para as participantes um amigo distante, que tinha chegado há pouco tempo na cidade. Foi explicado que elas teriam que ajudar o Mimão a entender as palavras desse mundo que eram diferentes das palavras do mundo em que ele vivia. Foi lido para as crianças o teste, que contava como era o Mundo de Mimão, e elas respondiam conforme as perguntas iam aparecendo no decorrer da história.

\section{RESULTADOS}

Após a transcrição e o levantamento dos dados, organizaram-se os dados de acordo com os aspectos morfológicos mais relevantes, tais como: conjugação verbal mais utilizada, tempo, modo e pessoa mais utilizada, types e tokens de formas verbais, tendo em vista os objetivos do trabalho. Cabe informar que os resultados referentes à aplicação dos testes com a participante bilíngue não renderam o que era esperado. Apesar de a criança bilíngue ter contato com a língua espanhola em casa, nas coletas dos testes em espanhol, ela não produziu uma quantidade relevante de verbos em espanhol para uma possível análise, embora compreendesse toda a aplicação dos testes, que foi realizada em espanhol. Isso se justificaria pelo fato de a participante estar inserida em uma comunidade em que a língua portuguesa é dominante e por ter conhecimento de que essa é a língua da pesquisadora com quem dialogava. Romaine (2004) explica que é muito comum que esse tipo de bilíngue entenda as línguas de seus pais, mas fale apenas a língua da comunidade na qual vive, especialmente em situações em que apenas um de seus pais fala a língua em casa. Nessas circunstâncias, segundo a autora, a criança até pode usar a outra língua, mas, em geral, não o faz. Um detalhe interessante é que, quando um dos testes estava sendo aplicado, e a participante foi indagada sobre com quem fazia tal atividade, ela usou uma palavra em espanhol para se referir ao seu pai. Veja-se no excerto da entrevista em (1). 
(1) Exemplo de uso do espanhol

Pesquisadora: !Vamos a baillar! Te gusta bailar? Bailas com quien?

C (4;6): com mi papi.(Trecho da transcrição da coleta).

A partir disso, subentende-se que a participante bilíngue tem os dois sistemas linguísticos ativos, entretanto, ela escolhe em qual língua se comunicar dependendo de com quem é o diálogo (ROMAINE, 2004). Mesmo não obtendo dados representativos em espanhol para posterior análise, houve grandes diferenças, em termos de vocabulário e de token, entre as participantes nas coletas em português. Para um melhor entendimento, serão comparados esses aspectos no próximo item dessa seção.

\subsection{Comparação dos dados}

Os resultados inferidos a partir do levantamento de dados mostraram a predominância de certas formas verbais comuns entre a participante bilíngue e a monolíngue. Contudo, a diferença maior foi o número de types produzidos por ambas as crianças. Abordar-se-ão as formas verbais encontradas durante a produção de dados das informantes, por forma verbal, em relação a types e a tokens dessas formas.

Os types dos verbos produzidos durante toda a coleta, assim como nas formas verbais de gerúndio e de particípio, para as duas participantes, mostraram uma predominância de verbos de primeira conjugação, mas a monolíngue produz o dobro de vocábulos verbais em comparação à bilíngue. Essa informação mostra indícios da concorrência de duas línguas no sistema linguístico da bilíngue. Em relação à produção de gerúndio, predominaram para as duas participantes formas verbais em primeira conjugação. Abaixo estão os quadros da comparação da produção das participantes: 
Quadro 4 - Types de verbos produzidos nos testes

\begin{tabular}{|l|c|c|c|}
\hline & $\begin{array}{c}1^{\circ} \\
\text { Conjugação }\end{array}$ & $\begin{array}{c}2^{0} \\
\text { Conjugação }\end{array}$ & $\begin{array}{c}3^{0} \\
\text { Conjugação }\end{array}$ \\
\hline Monolíngue & 61 & 16 & 04 \\
\hline Bilíngue & 30 & 10 & 07 \\
\hline
\end{tabular}

As participantes produziram formas verbais do modo indicativo nos tempos presente, pretérito perfeito e pretérito imperfeito. Com relação às pessoas verbais, predominou a terceira pessoa do singular para a participante monolíngue em todos os tempos e para a bilíngue somente no presente do indicativo, no restante a diferença entre a primeira e a terceira pessoa foi praticamente nula. Nesses tempos verbais, também, dobrou o número de produção da monolíngue em relação à bilíngue. Porém, no pretérito imperfeito, a participante bilíngue produziu mais formas verbais que a monolíngue. Verifique-se abaixo o número de types nos tempos verbais produzidos.

Quadro 5 - Types de pessoas no presente do indicativo

\begin{tabular}{|l|c|c|c|}
\hline & $\begin{array}{c}1 \text { 을 } \\
\text { Do } \\
\text { Singular }\end{array}$ & $\begin{array}{c}\text { 3o pessoa } \\
\text { do } \\
\text { singular }\end{array}$ & $\begin{array}{c}\text { 3o pessoa } \\
\text { do } \\
\text { plural }\end{array}$ \\
\hline Monolíngue & 16 & 29 & 04 \\
\hline Bilíngue & 13 & 14 & 0 \\
\hline
\end{tabular}

Quadro 6 - Types de pessoas no pretérito perfeito

\begin{tabular}{|l|c|c|c|}
\hline & $\begin{array}{c}1^{\circ} \text { Pessoa } \\
\text { Do } \\
\text { Singular }\end{array}$ & $\begin{array}{c}3^{\circ} \text { pessoa } \\
\text { do } \\
\text { singular }\end{array}$ & $\begin{array}{c}3^{\circ} \text { pessoa } \\
\text { do } \\
\text { plural }\end{array}$ \\
\hline Monolíngue & 16 & 12 & 0 \\
\hline Bilíngue & 6 & 6 & 1 \\
\hline
\end{tabular}


Quadro 7 - Types de pessoas do pretérito imperfeito

\begin{tabular}{|l|c|c|c|}
\hline & $\begin{array}{c}1 \text { 을 } \\
\text { Do } \\
\text { Singular }\end{array}$ & $\begin{array}{c}3^{\circ} \text { pessoa } \\
\text { do } \\
\text { singular }\end{array}$ & $\begin{array}{c}\text { 3 pessoa } \\
\text { do } \\
\text { plural }\end{array}$ \\
\hline Monolíngue & 1 & 2 & 1 \\
\hline Bilíngue & 2 & 8 & 0 \\
\hline
\end{tabular}

Outro aspecto decorrente do levantamento dos dados foi a diferença dos resultados nos testes das coletas da participante bilíngue. Existe uma distinção entre o português e o espanhol em relação à formalidade de tratamento entre as pessoas do discurso. No espanhol, usa-se para uma conversa informal o pronome tu (FANJUL, 2005), que em português, em sua forma conjugada segundo a norma padrão (ex. tu foste, tu fizeste), é utilizado para situações formais (CUNHA, CINTRA, 2008). A participante bilíngue, na coleta em espanhol, produziu menos verbos em terceira pessoa do que na coleta em português, como demonstrado no quadro abaixo em relação aos dados produzidos no presente do indicativo.

\section{Quadro 8-Types do pessoas do presente do indicativo}

\begin{tabular}{|l|c|c|}
\hline \multicolumn{1}{|c|}{ TYPE } & Types 1ํ $^{\circ}$ pessoa singular & Types 3ํ pessoa singular \\
\hline $\begin{array}{l}\text { Coleta } \\
\text { Português }\end{array}$ & 13 & 14 \\
\hline $\begin{array}{l}\text { Coleta } \\
\text { Espanhol }\end{array}$ & 8 & 2 \\
\hline
\end{tabular}

Embora a participante não tenha produzido formas verbais em segunda pessoa, tanto na coleta em português quanto em espanhol, há um decréscimo representativo nos types de primeira e terceira pessoa. Nos testes em português, a diferença entre essas pessoas é praticamente nula, já nos testes em espanhol a produção de verbos em primeira pessoa é praticamente $80 \%$ a mais do que na terceira pessoa. Presume-se, então, que a participante bilíngue demonstra sensibilidade ao sistema linguístico do espanhol, mostrando assim uma possível consciência dessa língua e, com isso, dando indícios de esse idioma está ativo em 
seu sistema linguístico.

No teste com pseudopalavras, nenhuma das participantes respondeu aos questionamentos utilizando as palavras inventadas. Suas respostas às indagações feitas pela pesquisadora correspondiam a verbos que elas já dominavam da língua portuguesa. Porém, a maioria dos verbos correspondia ao tempo verbal solicitado.

\section{Quadro 9 - Levantamento do tempo verbal produzidos no teste das pseudopalavras}

\begin{tabular}{|l|c|c|c|}
\hline & $\begin{array}{c}\text { Tempo } \\
\text { verbal adequado }\end{array}$ & $\begin{array}{c}\text { Tempo } \\
\text { verbal inadequado }\end{array}$ & $\begin{array}{c}\text { Não } \\
\text { Respondeu }\end{array}$ \\
\hline Monolíngue & 6 & 1 & 2 \\
\hline Bilíngue & 5 & 3 & 1 \\
\hline
\end{tabular}

É importante salientar que foi na aplicação desse teste a participante bilíngue produziu verbos da sua L2. Na coleta em espanhol, todas as respostas dadas a esse teste foram nessa língua, entretanto apenas um type verbal, com tokens no presente do indicativo e na forma de particípio. É instigante pensar nesse dado, visto que somente nesse momento a criança produziu essas formas verbais. $O$ questionamento que surge a partir desse levantamento é que, se ela utiliza somente o espanhol para se comunicar com seu pai, que é sua referência nesse idioma, porque ao lidar com palavras que não fazem parte de seu vocabulário ela utilizou esses verbos? Pressupõe-se, com isso, que, mesmo que a criança tenha esse discernimento sobre qual língua usar conforme o seu interlocutor, ela ainda não tem consciência exata sobre esse fato, visto que no momento em que se deparou com um vocabulário desconhecido produziu verbos em espanhol com a pesquisadora que já havia sido identificada como falante do português. Também pode ser considerada a atenção que é necessária para responder a tais perguntas, em havendo dois sistemas linguísticos concorrentes. A participante prestou mais atenção às palavras que não conhecia do que a escolher o sistema linguístico específico para se comunicar, sendo indispensável que bilíngues controlem a atenção para um sistema específico para, assim, perceber em qual língua devem se comunicar (BIALYSTOK, 2009). 


\section{ANÁLISE}

A partir da análise dos dados, perceberam-se diferenciações entre as participantes, mesmo olhando somente para a morfologia verbal referente ao português. Foram verificadas distinções na produção, quanto ao léxico verbal, e quanto à complexidade das formas verbais produzidas, durante as coletas ${ }^{6}$ que serão discutidas nos próximos itens dessa seção.

\subsection{Léxico verbal}

Os dados obtidos através da pesquisa feita confirmaram o pressuposto de Romaine, com relação ao tamanho do vocabulário bilíngue, visto que o número de tokens verbais produzidos pela monolíngue $(\mathrm{N}=244)$ foi quase o dobro do produzido pela bilíngue $(\mathrm{N}=143)$.

A partir disso, evidencia-se uma suposta vantagem do vocabulário lexical da participante monolíngue em relação ao da bilíngue, já que na aquisição de duas línguas simultâneas existem dois léxicos competindo e, assim, o número de itens conhecidos é dividido por dois (ABUTALEBI, 2007).

\subsection{Complexidade}

Uma das distinções entre as produções das participantes que chamou a atenção, durante a análise dos dados, foi a produção de tempos e modos verbais complexos pela bilíngue. No levantamento de dados, observou-se que, mesmo tendo um número menor de tokens verbais nas coletas, $C(4 ; 6)$ produziu formas mais complexas, tanto na coleta em espanhol, quanto em português. Essas formas geralmente não são produzidas por crianças dessa faixa etária, e não apareceram na fala de I $(4 ; 8)$.

As formas verbais de que se fala encontravam-se no modo subjuntivo na primeira pessoa do singular, sendo produzidas nos testes em português e em espanhol $^{7}$. Os tempos verbais utilizados foram o presente, com a produção de seja e ganhe, e futuro, com a produção de for. A utilização dessas formas verbais complexas leva a supor que a criança bilíngue esteja em um nível mais avançado do desenvolvimento linguístico verbal em relação à monolíngue, apesar do vocabulário 
menor. A hipótese decorrente dessa constatação é que tamanho de vocabulário não pode ser correlacionado à complexidade morfológica ${ }^{8}$. Na verdade, a complexidade das formas verbais produzidas pela bilíngue podem ser evidências de vantagens cognitivas, visto que bilíngues apresentam uma melhor função executiva e extralinguística ${ }^{9}$ (ABUTALEBI, 2007), por exercitarem regiões cerebrais, durante o monitoramento das duas línguas, tornando-as mais flexíveis e, assim, aumentando habilidade de processar informações (BIALSTOK, 2009).

\section{CONSIDERAÇÕES FINAIS}

Este trabalho procurou trazer algumas contribuições concernentes ao desenvolvimento da morfologia verbal, por meio de um estudo comparativo entre as produções de duas crianças - uma bilíngue e outra monolíngue.

Com base no referencial teórico apresentado na fundamentação, concluiu-se haver diferenças significativas entre as produções das duas informantes, se comparado o vocabulário produzido por ambas em relação a types e atokens. Sem dúvida, a criança bilíngue apresentou um léxico verbal inferior à monolíngue, porém mais complexo em termos de produção verbal do português, visto que essa informante produziu formas verbais no subjuntivo, vocábulos verbais complexos para a sua faixa etária. Acredita-se, então, que mesmo com léxico verbal menos numeroso (inferior), a bilíngue apresenta um desenvolvimento linguístico igual ou superior à monolíngue- tendo-se em vista os dois sistemas linguísticos concorrentes-, o que iria contra o pressuposto de que bilíngues apresentam uma aquisição mais demorada ${ }^{10}$ (ROMAINE, 2004).

Com isso, espera-se que este artigo possa suscitar mais questionamentos e pesquisas sobre esse fenômeno, assim como se pretende aprimorá-lo em futuros trabalhos, de vez que os dados foram coletados com apenas dois sujeitos, não permitindo generalização.

\section{NOTAS}

\footnotetext{
${ }^{1}$ Graduada em Letras pela Universidade Federal do Pampa.

${ }^{2}$ Prof. Adjunto II da Universidade Federal do Pampa. Doutor em Linguística pela PUCRS.

${ }^{3}$ Formas morfológicas regularizadas produzidas pelas crianças que estão adquirindo a linguagem.
} 
Essas formas não são vistas como erros, mas como formas variantes concorrentes com a gramática do adulto (LORANDI, 2007).

${ }^{4}$ Para uma melhor compreensão do jogo, o tabuleiro está nos anexos deste trabalho.

${ }^{5}$ Pseudopalavras são palavras inventadas que buscam averiguar se a criança consegue aplicar sufixos morfológicos a bases desconhecidas. Acredita-se na importância desse recurso, pois é nesse momento que a criança demonstra sensibilidade aos recursos morfológicos e que não apenas decorou por meio mecanismo do input recebido. (BERKO,1958; LORANDI, 2011; LORANDI; KARMILOFF-SMITH, 2012).

${ }^{6}$ Para a análise dos dados, foram considerados apenas os verbos da coleta em português da participante bilíngue, devido à pequena quantidade de dados produzidos em espanhol.

${ }^{7}$ Nesse caso, o verbo da coleta em espanhol estava em português.

${ }^{8}$ É claro que seria necessário um maior número de dados para uma verificação mais apurada dessa possível correlação.

${ }^{9}$ São mais criativos, possuem melhor desempenho acadêmico, maior habilidade em matemática, lógica e comunicação (ABUTALEBI, 2007).

${ }^{10}$ Neste trabalho, a análise dos dados levou a este entendimento. Porém, sabe-se que é preciso um maior número de dados para essa correlação.

\title{
VERBAL MORPHOLOGICAL ACQUISITION IN A COMPARATIVE STUDY BETWEEN BILINGUAL AND MONOLINGUAL CHILDREN
}

\begin{abstract}
This study aims to present the results of the research made about theacquisition of verbal morphology. Two children were compared; One bilingual (Portuguese and Spanish) and another monolingual (Portuguese) in order to problematize topics linked to the verbal vocabulary in Portuguese. As theoretical foundations, the project is grounded on the Romaine's studies (2004) about bilinguals, assuming that the development of two languages are competing in the linguistic system brings up differences in the vocabulary between monolinguals and bilinguals. The methodology used in the research was composed by the studies of Berko (1958) and Lorandi's (2011), about the verbal words production. The results of the data evaluation points out that there are really relevant vocabulary differences between the children analyzed, but they provoked reflection about the bilingual and his choice of the language he uses depending on the context and, principally, his interlocutor. It is been looking forward this project could be a complementation for the language
\end{abstract}


studies about bilinguals, as well as improve it in future projects in order to confirm certain results.

Keywords: Language Acquisition. Verbal Morphology. Bilingualism. Vocabulary.

\section{REFERÊNCIAS}

ALCOBA, Santiago Rueda. Morfología del verbo español: conjugación y derivación deverbal. In: VIDE, Carlos Martins (Org.). Lenguajes naturales y lenguajes formales. Barcelona: Publicaciones de la Universidad, 1991. p. 87-119

ABUTALEBI, L.; GREEN, D. Bilingual language production: the neurocognition of language representation and control. Journal of Neurolinguistics, 2007. Disponível em: <www.journals.elsevier.com/journal-of-neurolinguistics $>$. Acesso em: 13 jan. 2013.

BERKO, Jean. The child's learning of English morphology. Word, n. 14, p.150-177, 1958.

BIALYSTOK, Ellen. Factors in the growth of linguistic awareness. Child Development, n. 57, p. 498-510, 1986.

. Bilingualism: the good, the bad, and the indifferent. Bilingualism: Language and Cognition, v. 12, n. 1, p. 3-11, 2009.

BUSQUETS, Loreto; BONZI, Lidia. Los verbos em espanõl. Madri: Verbum, 1993.

CÂMARA JR, Joaquim Mattoso. Estrutura da língua portuguesa. 4. ed. Petrópolis: Vozes, 1973.

CLARK, Eve. Early Words. In: Cambridge University Press, 2010. . First language acquisition. 2. ed. Cambridge:

. Coining new words: old and new word forms for new meanings. In: MENN, L.; RATNER, B. N. (Orgs.). Methods for studying language acquisition. London: Laurence Erlbaum Associates, 2009.

CUNHA, C.; CINTRA, L. Nova gramática do português contemporâneo. 5. ed. Rio de Janeiro: Lexicon, 2008.

EDWARDS, John. Foundations of Bilingualism. In: BHATIA, Tej K.; RITCHIE, William C. The handbook of bilingualism. Malden: BlackwellPublishing, 2006. p. 7-30.

FANJUL, Adrián. Gramática y práctica de español para brasileños. São Paulo: Moderna, 2005. 
INGRAM, D. First language acquisition: method, description and explanation. Cambridge: Cambridge University Press, 1989.

KARMILOFF-SMITH, A. Beyond modularity: a developmental perspective on cognitive science. Cambridge (MA): MIT, 1992. 234 p.

KARMILOFF, K.; KARMILOFF-SMITH, A. Pathways to language: from fetus to adolescent. Massachussets: Harvard University Press, 2001.

LORANDI, A. Formas morfológicas variantes na gramática infantil: um estudo à luz daTeoria da Otimidade. 2007. 185 p. Dissertação (Mestrado em Letras-Faculdade de Letras)-Pontifícia Universidade Católica do Rio Grande do Sul, Porto Alegre, 2006.

From sensitivity to awareness: the morphological knowledge of Brazilian children between 2 and 11 years old and the representational redescription model. 2011. Tese (Doutorado em Letras-Faculdade de Letras)-Pontifícia Universidade Católica do Rio Grande do Sul, Porto Alegre, 2011.

LORANDI, A.; CRUZ, C. R.; SCHERER, A. P. R.. Aquisição da linguagem. Verba Volant. , v. 2, p. 144-166, 2011.

LORANDI, Aline. KARMILOFF-SMITH Anette. From sensitivity to awareness: the morphological knowledge and the Representational Redescription Model. Letras de Hoje, Porto Alegre, v. 47, n. 1, p. 6-16, jan./mar., 2012.

MUÑOZ, Ignacio Bosque; BARRETO, Violeta Demonte. Gramática descriptiva de la lengua española. Madrid: Espasa Calpe, 1999.

ROMAINE, Suzanne. Bilingual language development. In: TROTT, K.; DOBBINSON, S.; GRIFFITHS, P. The child language reader. London: Routledge, 1999/2004. p. 287-303.

TUNMER, W.E., HERRIMAN, M.L. The development of metalinguisticawareness: a conceptual overview. In: HERRIMAN, M.L (Org.). Language awareness in children. Berlin: Springer-Verlag,1984. p.12-35. 


\section{ANEXO 1 - TESTE 1: JOGO DAS PRINCESAS PORTUGUÊS}

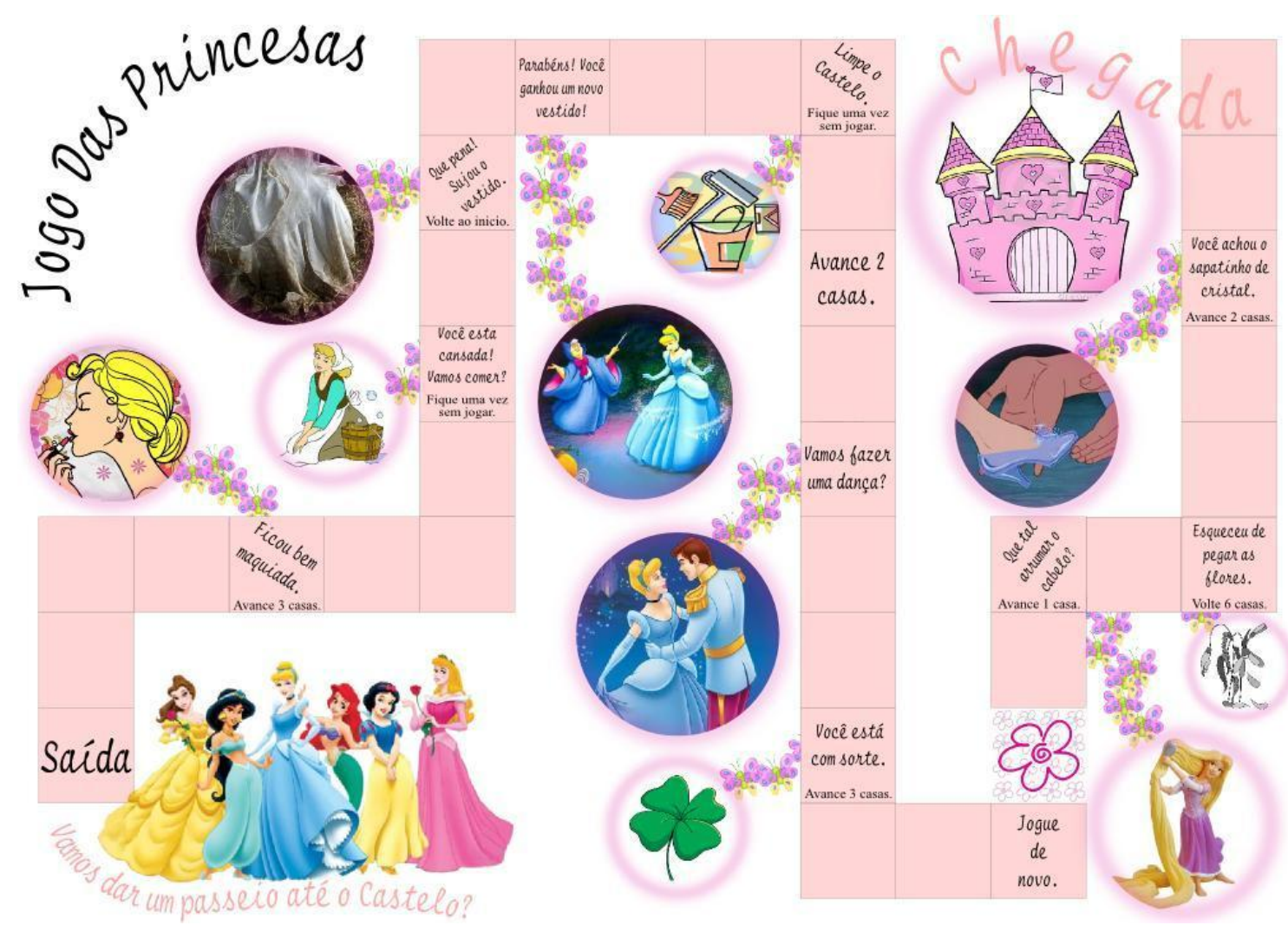


ANEXO 2 - TESTES 1: JOGO DAS PRINCESAS ESPANHOL

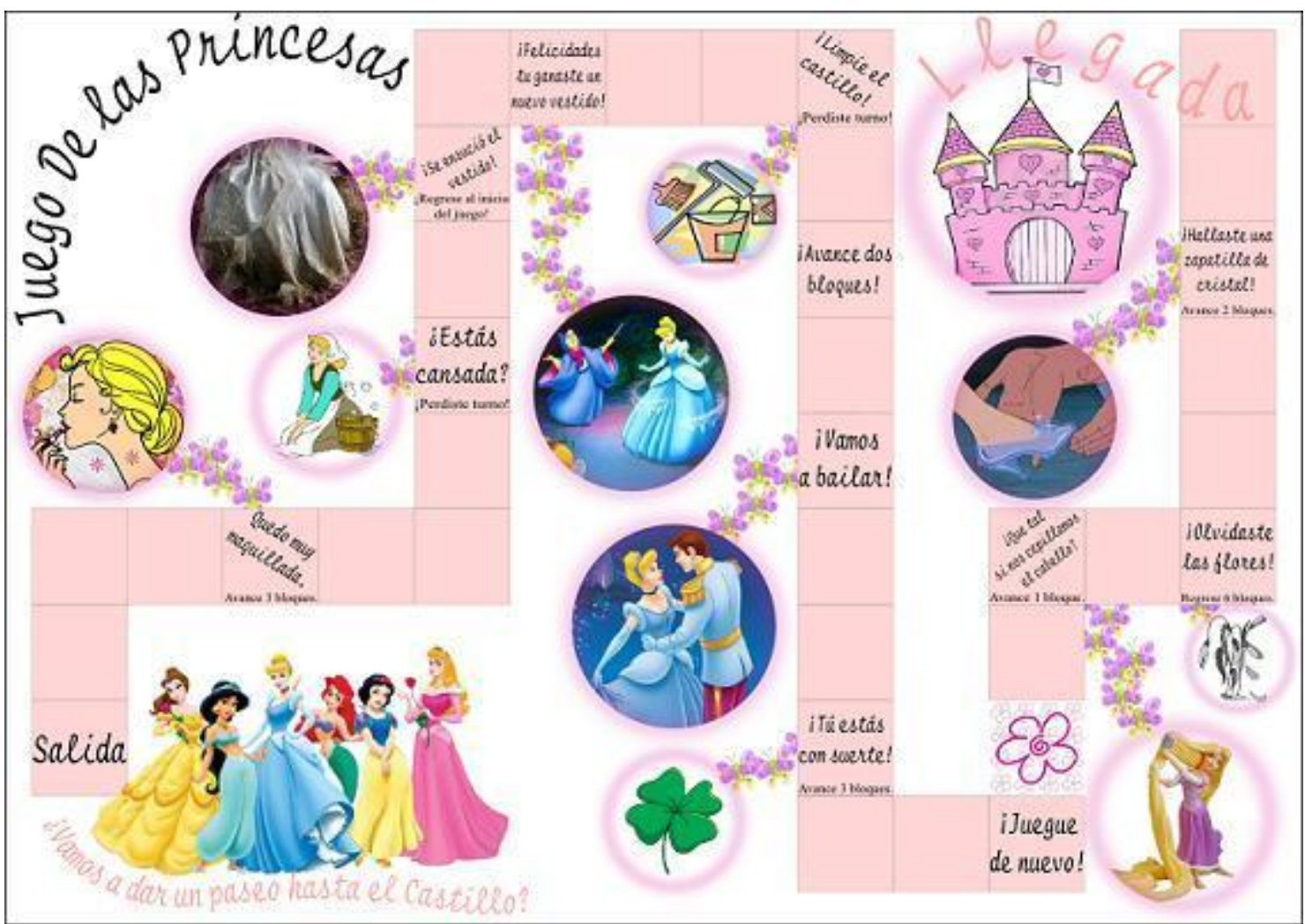

Signo [ISSN 1982-2014]. Santa Cruz do Sul, v. 38, Especial, p. 96-123, jul. dez. 2013. http://online.unisc.br/seer/index.php/signo 


\section{ANEXO 3 - TESTE 3: O QUE É O QUE É?}

Figura 1

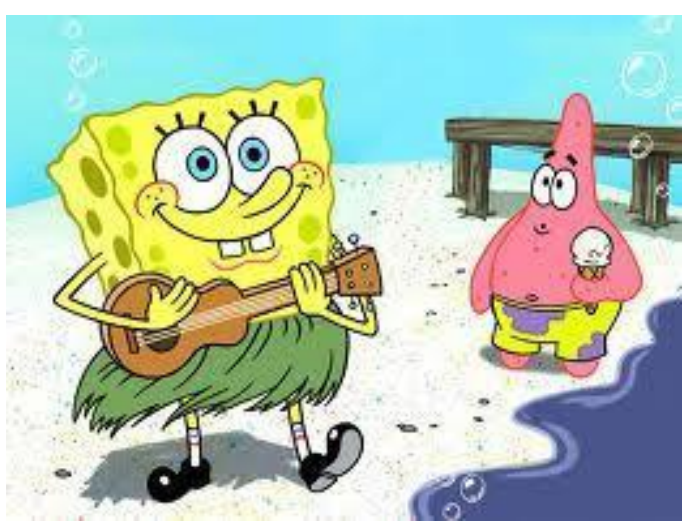

Figura 2

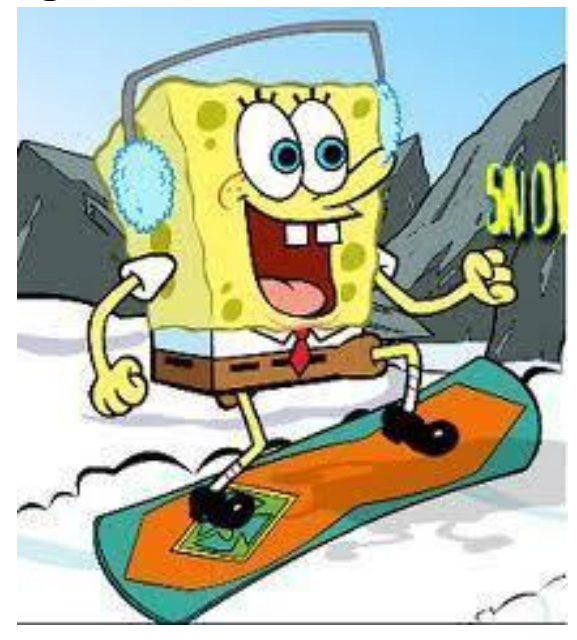

Figura 3

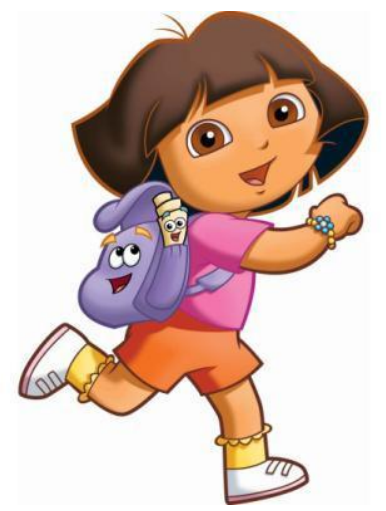

Figura 4

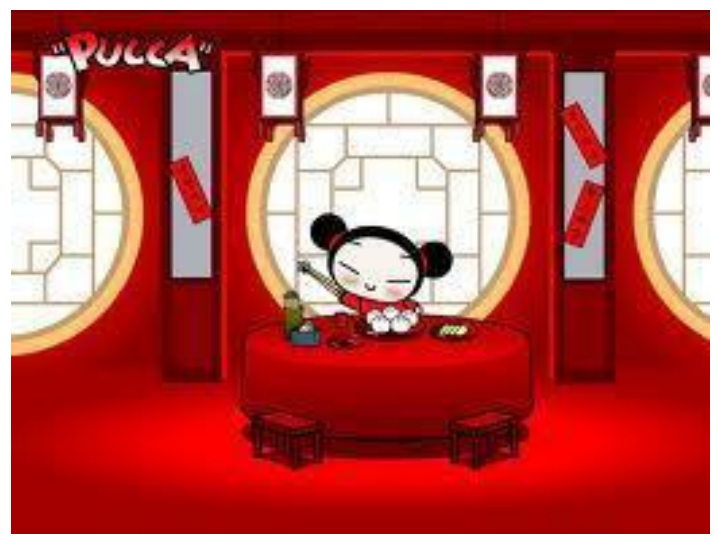

Figura 5

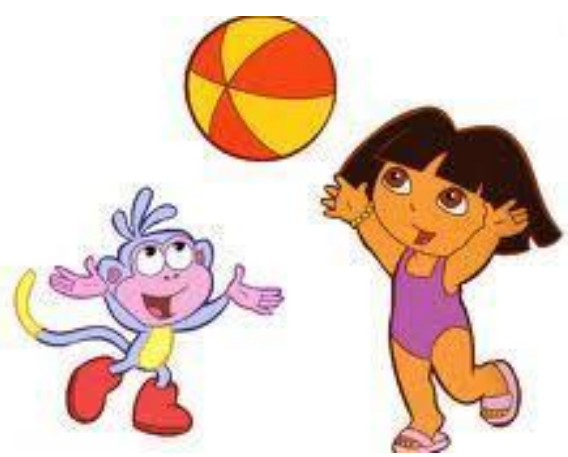

Figura 6

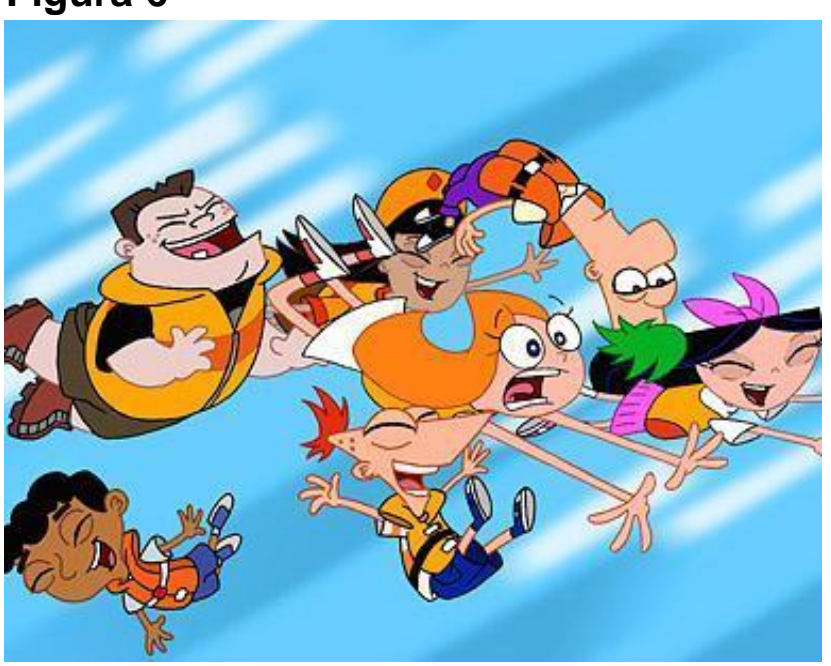


Figura 7

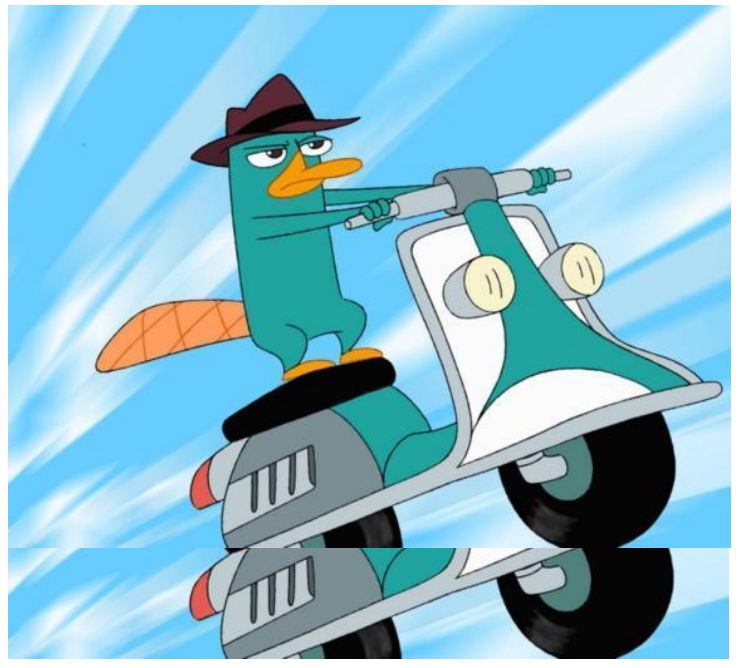

Figura 8

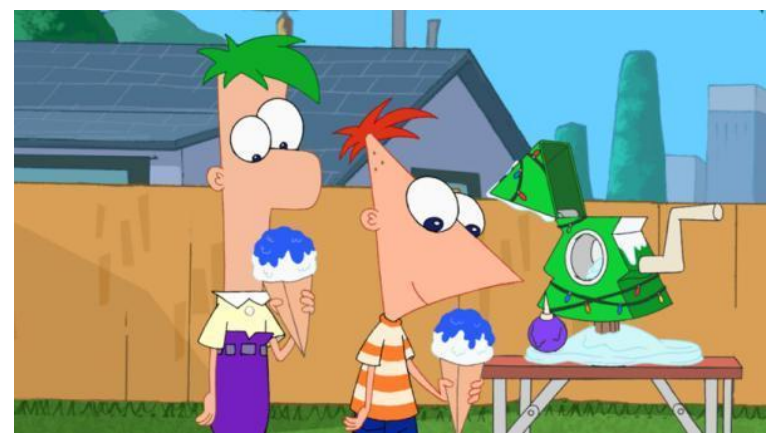

Figura 9

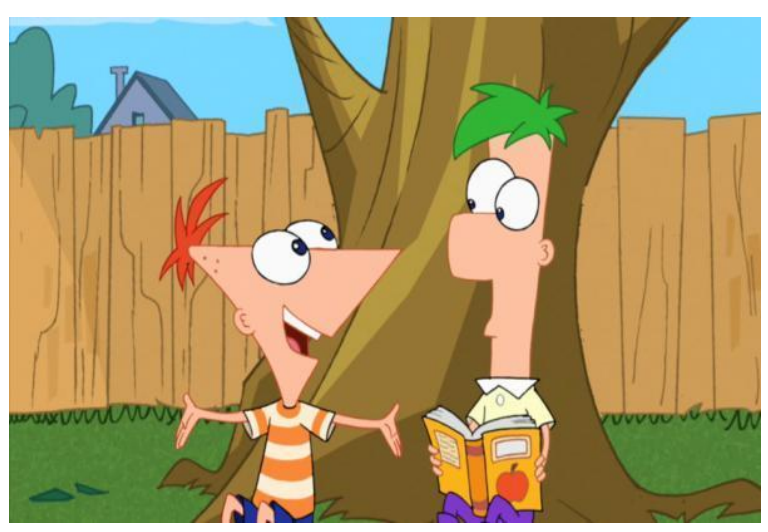




\section{ANEXO 4 - TESTE 4: IMAGEM DO MIMÃO}

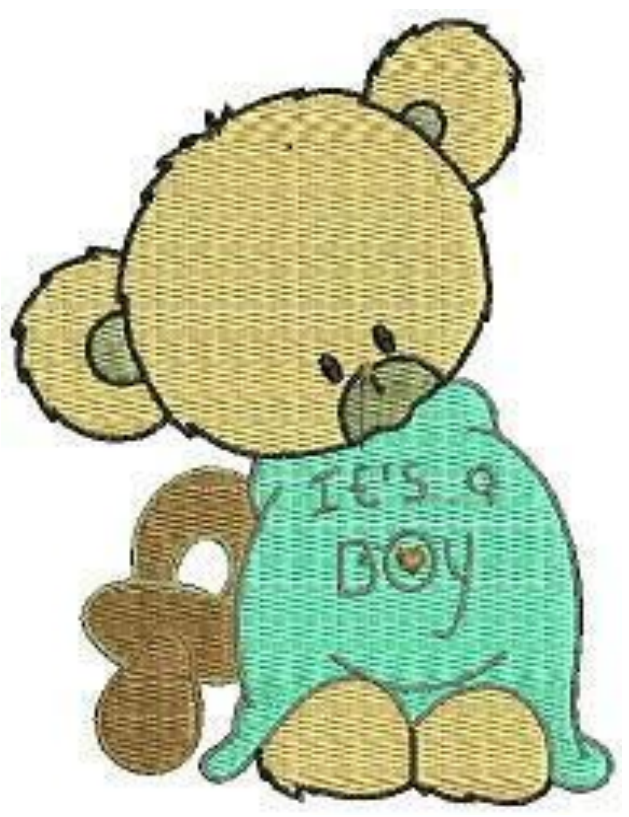




\title{
ANEXO 5 - TESTE 4: MUNDO DE MIMÃO- PORTUGUÊS
}

\author{
O MUNDO DE MIMÃO
}

Olá, meu nome é Mimão e eu vim de muito longe para cá. Vim para te conhecer e para conhecer as palavras e coisas deste mundo. Você pode me ajudar?

No meu mundo a gente jami, piscareja sempre que tem vontade, mas às vezes também chovalamos. Tu sabes o que é tudo isso? Não? Mas é muito fácil! É só imaginar que é uma palavra da sua língua e tentar usá-la, numa brincadeira bem divertida de usar palavras que não conhecemos até conhecermos! Queres saber um pouco mais da minha vida e do meu mundo e me ajudar a contar minha história? Vamos lá!

Eu andei, andei, andei e fui parar na casa da Liane e ela me contou sobre você. Queria muito ser seu amigo e te contar como é o meu mundo. O que você acha?

Lá no meu mundo a gente jami muito. Ontem mesmo a gente . Jami é aquilo que a gente faz quando ta numa festa, entende?Hoje nós poderíamos

Você vai a muitas festas? Eu adoro festas. O problema é que tenho um gatinho e quando saio sempre deixo ele sozinho. E ele sente muita saudade de mim, sabe? Quando chego das festas, por exemplo, ele está sempre piscarejando. Os gatos adoram piscarejar. Eu gosto também. sempre pro meu gatinho, assim conversamos. Antigamente eu , Ontem, antes de chegar, eu , mas agora não consigo mais. E aqui?

Lá, quando estamos tristes, nós costumamos cholavar, Hoje eu quando lembrei do meu mundo. Quando chove lá, as pessoas ficam gifingadas. Ontem mesmo eu me

Eu mitro sempre que estou com sede. Agora mesmo eu estou com vontade de . Ontem eu todo

o dia, cheguei cansando da viagem. É longa, você sabia?Me fala um pouco dos seus amigos... Você tem amigos? Eles vêm te visitar? Será que vão querem me conhecer?Eu sou seu amigo agora, né?!

Bom, vou dormir, que estou cansado. Posso voltar outro dia?

Beijo 


\section{ANEXO 6 - TESTE 4: MUNDO DE MIMÃO- ESPANHOL}

\section{EL MUNDO DE MIMÃO}

Hola, mi nombre es Mimão y yo vine de muy lejos haciaa cá. Vine para conocerte y para conocer las palabras y cosas de este mundo. ¿Usted puede ayudarme?

En mi mundo la gente jami, piscareja siempre que tiene ganas. ¿Tú sabes lo qué es todo eso? ¿No? ¡Pero es muy fácil! !Es solo imaginar que es una palabra de su lengua e intentar usarla, en un juego muy divertido de usar palabras que no conocemos hasta conocerlas! ¿Quieres saber un poco más de mi vida y de mi mundo y ayudarme a contar mi historia? ¡Vámonos!

Yo anduve, anduve, anduve y llegué a la casa de Liane y ella me contó de usted.

Quería mucho ser su amigo y contarte como es mi mundo. ¿Qué te parece?

Allá la gente Jami mucho. Ayer mismo nosotros Jami esaquello que hicimos cuando estamos en una fiesta, ¿entiende? Hoy nosotros podríamos ¿Usted va a muchas fiestas? Me encantan las fiestas. El problema es que tengo un gatito y cuando me voy a fiestas yo siempre le dejo solo. Y él me extraña, ¿sabes? Cuando llego de las fiestas, por ejemplo, el está siempre piscarejando. Los gatos aman piscarejar. También me gusta. Siempre_ para mi gatito, así hablamos. Anteriormente

Ayer, antes de llegar, , pero ahoraya no puedo más. ¿Y aquí

Allá, cuando estamos tristes nosotros tenemos la costumbre de . Hoy yo cuando me acordé de mi mundo.

Cuando llueve allá, las personas quedan Gifingadas. Ayer mismo yo me - Mitro siempre que tengosed. Ahora mismo tengo ganas de

Ayer todo el día, llegué cansado del viaje. Es largo, ¿sabe?Hábla me un poco de sus amigos... ¿Ustedes tienen amigos? ¿Ellos vienen a visitarte? ¿Van a querer conocerme? Yo soy su amigo ahora, i¿no?!

Bueno, voy a acostarme que estoy cansado. ¿Puedo volver otro día? Besos 